\title{
Special Aspects of Using the Wind Power Plants In the Power Supply System
}

\author{
Saken Koyshybaevich Sheryazov ${ }^{1, *}$, Sultanbek Sansyzbaevich Issenov ${ }^{2}$, Ruslan Maratbekovich Iskakov ${ }^{2}$, and Argyn \\ Bauyrzhanuly Kaidar ${ }^{2}$ \\ ${ }^{1}$ South Ural State Agrarian University, Institute of Agroengineering, 454000 Chelyabinsk, Lenin avenue, 75, Russian Federation \\ ${ }^{2}$ Saken Seifullin Kazakh Agrotechnical University, Faculty of Energy, 010000 Nur-Sultan, Zhenis avenue, 62, Republic of Kazakhstan
}

\begin{abstract}
The paper describes special aspects of using the wind power plants (wind turbines) in the power grid. The paper provides the classification and schematic presentation of AC wind turbines, analyzes the role, place and performance of wind power plants in Smart Grid systems with a large share of renewable energy sources. The authors also reviews a detailed analysis of existing AC wind turbines in this paper. Recommendations are given for how to enhance the wind power plants in smart grids in terms of reliability, and introduce the hardware used in the generation, conversion and interface systems into the existing power grid. After the wind power plants had been put online, the relevance of the Smart Grid concept for existing power grids was obvious. The execution of such projects is assumed to be financially costly, requires careful study, and development of flexible algorithms, but in some cases this may be the only approach. The analysis of using wind turbines shows that the structural configuration of wind power plants can be based on the principles known in the power engineering. The approaches may differ, not fundamentally, but in engineering considerations. it is necessary to point out that the method of controlling dual-power machines is quite comprehensive so that their wide use will face operational problems caused by the lack of highly professional specialists in electric drives. Therefore, it seems advisable to use square-cage asynchronous generators in wide applications. The paper shows that as the renewable energy sources are largely used in power grids, there is an issue of maintaining the power generation at a required level considering the variability of incoming wind energy. This results in the malfunctions in the operation of relay protection devices and emergency control automatics (RP and ECA), and the complicated control. Also, the standards of the CIS countries and regulatory documents miss the requirements for the wind turbine protections, taking into account their specialty causing the inefficient standard protective logic, which does not work correctly in a number of abnormal and emergency operating modes, and especially Smart Grid in power grids.
\end{abstract}

\section{Introduction and literature review}

PURPOSE. Analysis of the topology of the most wellknown wind power plants, determination of the most efficient and cost-effective wind turbines.

METHODS. Statistical, theoretical, factorial, and technical methods are used.

Today, one of the ways to preserve the environment and its ecology is the widespread use of alternative, environmentally friendly renewable energy sources (renewable energy). Another argument for renewable energy is that with its huge area (2.7 million $\mathrm{km} 2)$ and a low population density ( 5.5 people per $\mathrm{km} 2$ ), the Republic of Kazakhstan suffers with energy losses when it is delivered to remote consumers. In view of this, the comprehensive development of local renewable energy sources can be an economic and environmental alternative to large coal-fired power plants. One of the most dynamically growing commercial types of renewable energy is wind energy.
In 2009, the Law of the Republic of Kazakhstan titled On Support for the Use of Renewable Energy Sources came into force and the regulatory documents necessary for its implementation as well. The first wind power plants (WPP) in Akmola, Atyrau, South Kazakhstan and Almaty regions with a total installed capacity of over $160 \mathrm{MW}$ have started operating.

Currently, as the reserves of fossil fuels (coal, natural gas, peat, oil, etc.) become depleted, there is a tendency to develop and introduce renewable energy sources in the world, of which wind power plants (wind turbines) are the most promising [1-3]. However, the wide introduction of both wind turbines and other renewable energy sources into the power grid has brought a whole range of challenges related to the difficulties of managing and maintaining the stability of parallel operation.

For the solution of the above-mentioned problems, the Smart Grid concept was designed [4-7]. However, despite this, as shown in [6], the issues of high-quality

\footnotetext{
* Corresponding author: sakenu@yandex.ru
} 
operation of control systems and relay protection \& emergency automation systems, specifically for wind turbines, remain unaddressed when primary energy sources (wind, solar, etc.) are unstable. Therefore, the analysis of the role, place, and problematic aspects of the performance of wind power plants in the Smart Grid systems is challenging.

A large number of papers are devoted to the analysis of current wind power plants [1, 7-17]. The [1,7] provide a description of the key features of the main types of wind turbines without considering relay protection and automation. Also, [4] briefly describes control systems of wind generators and their role in Smart Grid systems. The [13-15, 17] deals with the analysis of the dynamic modes of wind turbines, while the matter of the implementation and performance of relay protection and automation in the wind generators are discussed in $[7,17]$. The existing codes $[8,11]$ refer to classifications of wind generators, but without taking into account a number of features of contemporary wind turbines.

A modern wind turbine is a sophisticated and costly electromechanical system for converting the primary wind energy into secondary electrical power. The leading manufacturers of wind turbines are currently: Siemens AG (Germany), Vestas Wind Systems A/S (Denmark), General Electric (USA), Fuhrländer AG (Germany), Senvion SE (Germany), Nordex SE (Germany) and Enercon (Germany). The single rated power of modern wind turbines ranges from a few kilowatts to $10 \mathrm{MW}$. Generally, most wind power plants are three-bladed units with a horizontal axis of rotation parallel to the direction of the wind flow. Based on the current state standard GOST R 51990, wind turbines are divided into four groups, in terms of the power rating: the first group (high power) - over $1 \mathrm{MW}$; the second (medium power) - from $100 \mathrm{~kW}$ to $1 \mathrm{MW}$; the third (low power) - from 5 to $100 \mathrm{~kW}$; the fourth (very low power) - less than $5 \mathrm{~kW}$ [8]. The leading countries, where the share of renewable energy is quite high, are Germany, Italy, Denmark, Spain, China, the Netherlands, and others. For example, according to $[9,10]$, the percentage of renewable energy in Germany was more than $20 \%$ by the end of 2019.

\section{Main Points}

Wind turbines are classified owing to many characteristics, the main of which are: the type of energy produced, power, operation with a constant or variable speed of rotation of the wind wheel, etc. Pursuant to GOST R51990, the wind power plants, depending on the type of power produced, are divided into two groups: mechanical and electrical. Electric wind power plants, in turn, are divided into DC and AC wind turbines (Fig. 1). In this paper, the authors focus on the consideration of exclusively AC electrical plants of the online subgroup.

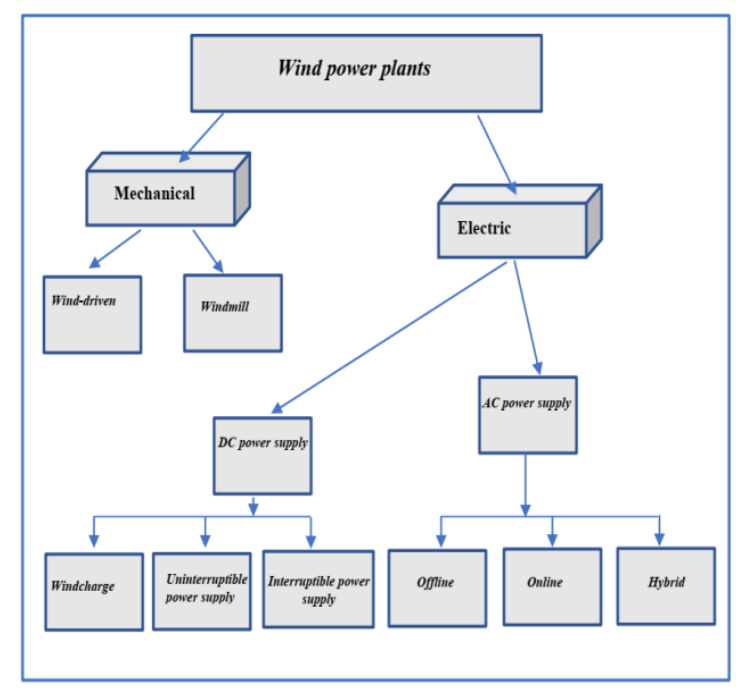

Fig. 1. General classification of wind turbines.

In $\mathrm{AC}$ electrical units, the principles of operate and methods of control differ from each other. Thus, the offline wind turbines are designed to operate in isolation for their own power system to supply power to a particular consumer.

Hybrid or system wind turbines are designed to operate in parallel with other power plants of comparable power (diesel generators, small hydroelectric power plants, etc.) for the common grid they build. Online wind turbines are designed to operate directly for parallel operation with power grids of incommensurably greater power $[4,8]$.

As is well known, a online wind generator is designed for parallel operation with power grids, the power of which is infinitely large or greater, however comparable with the rated power of the wind generator itself [11]. According to the available regulatory and technical documentation, there are two types of operation of online wind turbines: with a constant and variable a speed of rotation of the wind wheel, as shown in Fig. 2.

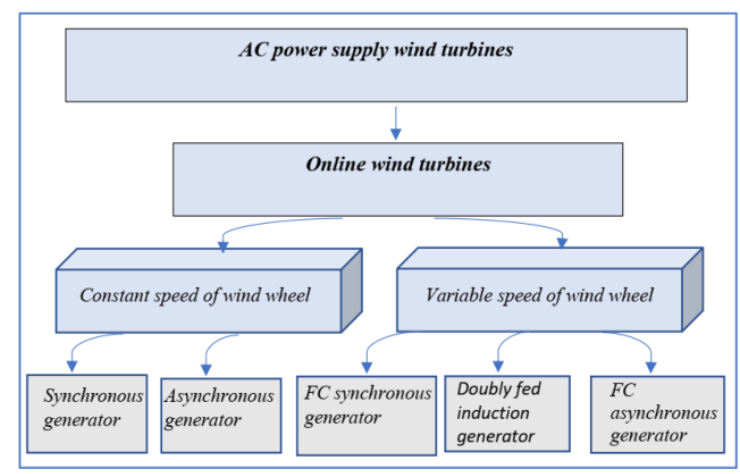

Fig. 2. Online wind turbines.

In the first case, the control method is the regulation of the wind wheel when using either a synchronous generator (SG) or an asynchronous generator (AG) in the power generation system. When it refers to the second case, the control method is the regulation of the wind wheel and the solid-state frequency converter, which can be carried out separately or jointly. Then the power 
generation system can include asynchronous generators with frequency converters, synchronous generators with frequency converters, or a doubly fed induction generator.

Analyzing the existing regulatory and technical documents in the former Soviet Union countries, it should be noted that these documents do not classify wind turbines by type of their location, namely, offshore (sea-based) and onshore (land-based). No classification of plants is available in terms of the presence or absence of a gearbox between the wind wheel and the generator.

In addition, the documents do not specify which type of generator should be included in the generation system for a particular group of wind turbines.

In practice, the most common types of wind power plants can be identified based on the actual state of windpower engineering:

- Wind turbines based on squirrel-cage asynchronous generators;

- Wind turbines based on doubly fed induction generators;

- Wind turbines based on synchronous generators with conventional DC excitation winding;

- Wind turbines based on permanent-magnet synchronous generators.

Normally, squirrel-cage asynchronous generators are installed on wind turbines with a capacity of up to 1 MW. Wind turbines based on doubly fed induction generators are available in the power range from 1 to 5 MW. Wind turbines based on permanent-magnet synchronous generators, and based on conventional excitation winding are used if the power is more than 3 MW.

Simplified charts of the main electrical connections of wind turbines with asynchronous generators are shown in Fig. 3.
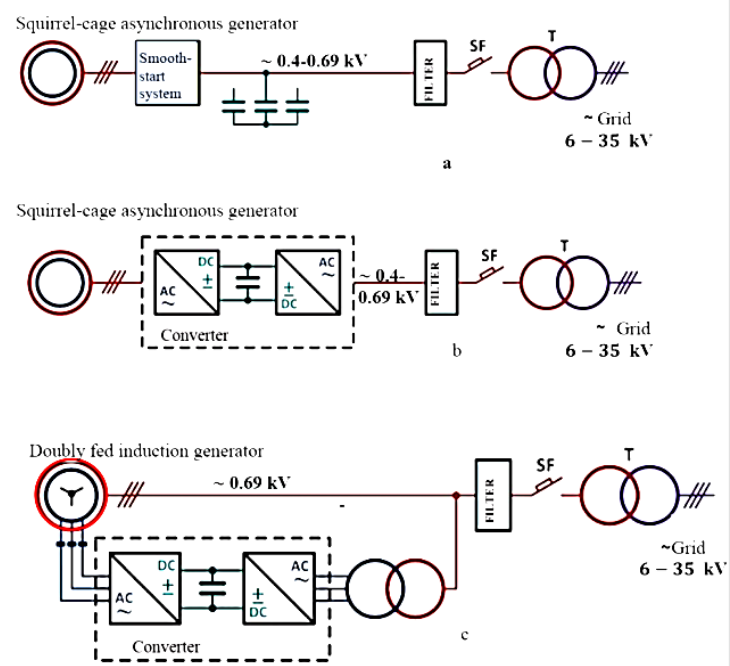

Fig. 3. Simplified charts of the main electrical connections of wind turbines with asynchronous generators: a - wind turbine based on directly connected squirrel-cage asynchronous generator; $b$ - wind turbine based on squirrel-cage asynchronous generator with frequency converter in stator circuit; $\mathrm{c}$ - wind turbine based on doubly fed induction generator.
Directly connected squirrel-cage asynchronous generators in the power grid (Fig. 3, a) are used at a constant angular speed, regardless of the wind speed. A key point of such wind turbines is the additional capacitors required to compensate for the consumption of reactive power. The advantages include simplicity and reliability, as well as a relatively low cost compared to other types of wind turbines. The main disadvantages include uncontrolled consumption of reactive power, low efficiency for wind speeds other than the rated one, transmission of wind speed fluctuations to the power grid, and the high mechanical stress. The control system of wind turbines with squirrel-cage asynchronous generators, and specifically the control of the generation output power, uses the following aerodynamic principles, such as speed loss control (passive control) and pitch control [12-14].

The connection of squirrel-cage asynchronous generators to the power system via a solid-state frequency converter (Fig. 3, b) is used at a variable angular speed, which allows generating a voltage of industrial frequency. The control of these wind turbines with pitch control and with the control of the frequency converter is on the side of the generator voltage. The disadvantages include a decrease in the efficiency of the machine at a shaft speed less than the rated value, an issue of regulating the reactive power, and the quality of the generation voltage because of the frequency converter.

Figure 3, b shows the layout of a wind turbine based on doubly fed induction generator. Wound-rotor asynchronous generators are usually used as doubly fed induction generators.

The three-phase stator winding of the generator is connected via a step-up transformer to the power grid. A solid-state frequency converter is connected to the rotor winding, which is necessary to change the angular frequency of rotation in a certain range. This range is limited both by the technical characteristics of the frequency converter itself and by the mechanical parameters of the wind generator.

A positive feature is the ability to control the power factor and the reactive power of the doubly fed induction generator. The disadvantages include a brush woundrotor machine, which affects the reliability of the wind turbine, and the issues related to the quality of the grid voltage due to the use of a frequency converter. Economically, the wind turbine based on a doubly fed induction generator is cheaper than plants using costly frequency converters in the generator voltage circuit.

The control system of the wind turbine based on a doubly fed induction generator includes pitch control, maximum power control, or MPPT-controller (Maximum Power Point Tracking), and control of the frequency converter in the wound-rotor circuit $[4,12$ 17].

Figure 4 shows simplified charts of the main electrical connections of wind turbines based on synchronous generators. 


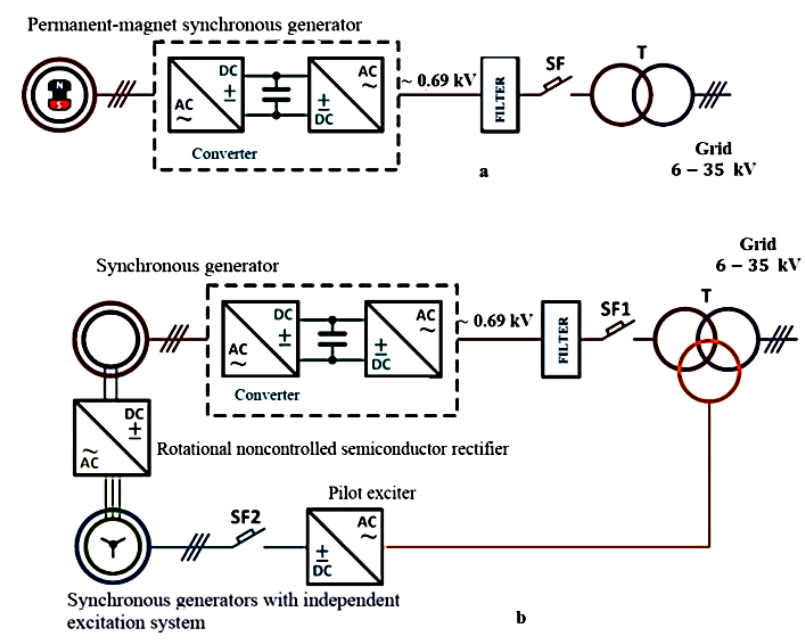

Fig. 4. Simplified charts of the main electrical connections of the wind turbine based on synchronous generators: a - wind turbines based on permanent-magnet synchronous generators; $b$ - wind turbines based on synchronous generators with an independent brushless excitation system.

This kind of wind turbines usually has no gearbox, which implies a direct connection between the generator and the wind turbine. The stator of the synchronous generator is connected, as in the case of a permanentmagnet synchronous generator (Fig. 4, a), and in the case of a synchronous generator with a conventional excitation system (Fig. 4, b), to the grid using a solidstate frequency converter, which allows the turbine to operate at an adjustable angular speed. Currently, the most common are wind turbines based on synchronous silent-pole generators with a brushless excitation system. Permanent-magnet synchronous generators include permanent rotor magnets, which makes it possible to reduce the cost and simplify the design.

However, such machines have the inherent drawback of losing the required magnetic properties during operation (demagnetization). Further, the disadvantages of the above circuits with synchronous generators include the high cost of wind turbines compared to other types of wind turbines, the impact on the deterioration of energy quality in the generation, and difficulties in their control.

The control system of the wind turbines based on synchronous generators is similar to wind power plants based on doubly fed induction generators $[4,12]$.

In the Smart Grid systems, wind power plants are one of the key renewable energy sources. Usually, wind turbines form wind parks or wind power plants with a total capacity of several tens of kilowatts to hundreds of MW. Thus, the Yereymentau wind farm (Fig. 5) near Pavlodar consists of 22 wind turbines, and generates up to $45 \mathrm{MW}$. The unit capacity of one wind turbine is 2,050 kW (2,05 MW), the wind farm has its own substation - wind power station Yereymentau-1, wich produces $35 / 220 \mathrm{kV}$, with a 63MVA transformer (Siemens). The $220 \mathrm{kV}$ overhead line is $8 \mathrm{~km}$ in length (double-circuit).

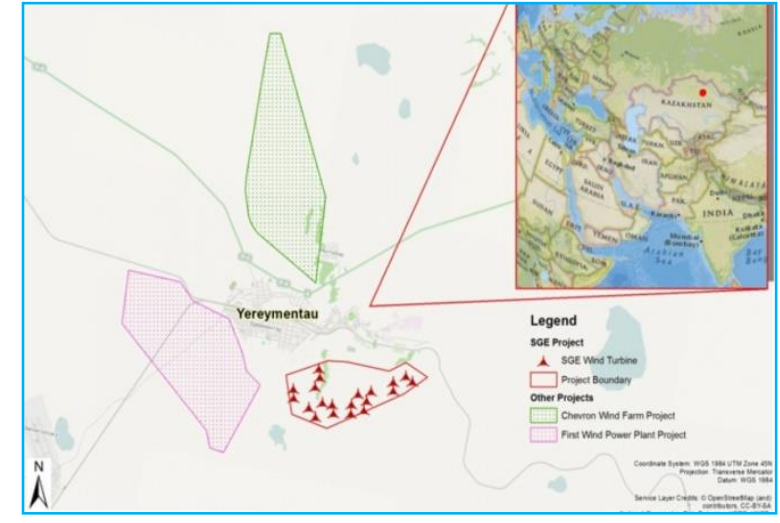

Fig. 5. Location of the wind farm Yereimentau-1.

As shown in [7], with a large share of renewable energy in the power grids, there is an issue of maintaining the required level of power generation due to the instability of primary natural energy sources. This results in the malfunctions in the operation of relay protection devices and emergency control automatics (RP and ECA), and the complicated control [18, 19]. Also, the standards of the CIS countries and regulatory documents miss the requirements for the wind turbine protections, taking into account their specialty causing the inefficient standard protective logic, which does not work correctly in a number of abnormal and emergency operating modes, and specifically in Smart Grid systems.

The main problem of emergency modes of operation is the synchronization of the units with each other and with the grid. When connected to a shared grid, synchronization by voltage, frequency, and phase is required. If the synchronization is insufficient at the time of connecting the wind turbine to the power grid, for example, by phase or voltage, currents may appear that exceed the nominal value by 6-10 times. Therefore, in the Kaliningrad Region of Russia, a wind farm of 22 VESTAS (Denmark) 150/30 wind turbines failed. Oddly enough, one generator failed at the same wind farm due to a lightning strike.

In addition, the issue of wind energy is the variability of wind potential, both in terms of time of day and season. Exemplarily, this year, weather conditions caused the wind farms of Texas (USA) and a number of other states to shut down. Therefore, it is impractical to use wind farms as a basic source of power supply in areas with unfavorable weather conditions. Given that up to 60 percent of wind farms are located in three countries, the United States, China and Germany, as well as the fact that the issues of wind energy due to weather factors in the United States and in Europe, including Germany, the approach of a complete transition to wind power plants and solar energy is probably premature.

China has other issues. The matter of mismatch of load and generation schedules, charging and lobbying of energy companies with conventional generation of their interests, which causes the lack of demand for up to $37 \%$ of wind energy, energy storage, shortcomings of grid infrastructures, generation and consumption centers do not coincide, etc. 
One of the solutions to the above-mentioned engineering issues is the upgrade and design of new relay protection and automation systems of wind turbines, for example, the development of adaptive protections using the protocol of the International Electrotechnical Commission IEC 61850 [4-7], which will drive the increase in reliability.

With the existing conventional power plants, existing grids, the issue of the Smart Grid concept becomes topof-the-agenda when putting wind farms online. These projects are costly, require careful study and flexible algorithms. But in some cases, this is the only approach. So the destruction of the old system and the construction of a new one under the existing loads is almost impracticable since it requires addressing the issue of financing, dismantling the old system, backup power systems when bringing the old system out of service for upgrade, the upgrade itself, issues of automation and relay protection, etc.

The analysis shows that structurally the wind farms can be based on the principles known in the energy industry. The classification and structural configuration are given in the paper. The implementation may vary, but it is not essential. These are engineering considerations. Converters based on power transistors and doubly-fed electric machines designed and being designed by the scientific school of Yu. G. Shakaryan (Moscow, All-Union Electric Power Research Institute, FGC UES, R\&D Centre) may have some originality. The method of controlling doubly-fed electric machines is extremely comprehensive, and with wide application there will be operational issues caused by the lack of a sufficient number of highly professional electric drive operators. Therefore, it seems advisable to use squarecage asynchronous generators in wide applications.

Transistor converters based on power transistors for wind power engineering, including inverters with pulsewidth modulation, multi-stage MLID converters, issues of testing, control, protection, etc. were repeatedly cited in the papers of authors in Kazakhstan, Russia, Switzerland, Germany, and other countries and in the monograph called Theory and Practice of Energy Converters and published by Lambert Academic Publishing, Saarbrücken, Germany, 2014 (p. 461) [5]. This paper does not aspire to identify all the well-known companies and countries, specifically since the operated wind farms are designed and constructed on the same principles.

\section{Results}

In power grids, it is advisable to use a wind turbine based on a direct-on-line asynchronous generator at a constant angular speed, regardless of the wind speed. It is necessary to use additional capacitor banks to compensate for the reactive power. The advantages include simplicity and reliability, as well as a relatively low cost compared to other types of wind turbines. The main disadvantages include uncontrolled consumption of reactive power, low efficiency for wind speeds other than the rated one, transmission of wind speed fluctuations say the power to the power grid, and the high mechanical stress. The control system of wind turbines based on squirrel-cage asynchronous generators, and specifically the control of the generation output power, uses the following aerodynamic principles, such as speed loss control (passive control) and pitch control.

Connection of a wind turbine based on an asynchronous generator to the power grid via a solidstate frequency converter is used at a variable angular speed, which allows generating a power-frequency voltage. The control of these wind turbines with pitch control and with the control of the frequency converter is on the side of the generator voltage. The disadvantages include a decrease in the efficiency of the machine at a shaft speed less than the rated value, an issue of regulating the reactive power, and the quality of the generation voltage because of the frequency converter.

A positive feature is the ability to control the power factor and the reactive power of the doubly fed induction generator. The disadvantages include a brush woundrotor machine, which affects the reliability of the wind turbine, and the issues related to the quality of the grid voltage due to the use of a frequency converter. Economically, the wind turbine based on a doubly fed induction generator is cheaper than plants using costly frequency converters in the generator voltage circuit.

The wind turbines based on synchronous generators have no gearbox, which implies a direct connection between the generator and the wind turbine. The stator of the synchronous generator is connected, as in the case of a permanent-magnet synchronous generator, and in the case of a synchronous generator with a conventional excitation system, to the grid using a solid-state frequency converter, which allows the turbine to operate at an adjustable angular speed.

Currently, the most common are wind turbines based on synchronous silent-pole generators with a brushless excitation system. Permanent-magnet synchronous generation systems include permanent rotor magnets, which makes it possible to reduce the cost and simplify the design. However, such machines have the inherent drawback of losing the required magnetic properties during operation (demagnetization). Further, the disadvantages of the above circuits with synchronous generators include the high cost of wind turbines compared to other types of wind turbines, the impact on the deterioration of energy quality in the generation, and difficulties in their control.

With a large share of renewable energy in the power grids, there is an issue of maintaining the required level of power generation due to the instability of primary natural energy sources. This results in the issues in the operation of relay protection devices and emergency control automatics (RP and ECA), and the complicated control. Also, the standards of the CIS countries and regulatory documents miss the requirements for the wind turbine protections, taking into account their specialty causing the inefficient standard protective logic, which does not work correctly in a number of abnormal and emergency operating modes, and specifically in Smart Grid systems. 
One of the solutions to the above issues is the upgrade and design engineering of new systems of relay protection and automation for wind turbines, e.g. the development of adaptive protections using the IEC 61850 protocol, which increases the reliability of the system.

\section{Conclusion}

The paper focuses on the structural configurations of wind power plants. Regardless of the company and country of manufacture, all structural configurations are based on well-known methods, including generation using doubly fed electric machines.

A detailed analysis of current wind power plants was made resulting in that wind turbines based on doubly fed induction generators are the most rational and costeffective units. From a practical (operational) standpoint, squirrel-cage asynchronous generators are advisable to use.

It is found that within in the Smart Grid systems, wind power plants are one of the key renewable energy sources, however having a number of specific features of operation. To improve the reliability of the wind turbine operation, the ways have been proposed of how to upgrade the relay protection and automation by designing adaptive protections using the IEC 61850 protocol.

\section{References}

1. Sheryazov, S. K.; Shelubaev, M. V.; Obukhov, S. G. Renewable Sources in System Distributed Generation. International Conference on Industrial Engineering, Applications and Manufacturing, ICIEAM 2017.

2. Sheryazov, S.K., Ptashkina-Girina, O.S. Increasing power supply efficiency by using renewable sources. 2nd International Conference on Industrial Engineering, Applications and Manufacturing. ICIEAM. 2016.

3. Sheryazov, S.K., Ptashkina-Girina, O.S., Nizamutdinova, N.S. Technological and Economic Evaluation of the System of Heat Supply with the Usage of Renewable Sources of Energy. 2018 International Multi-Conference on Industrial Engineering and Modern Technologies (FarEastCon). Publisher: IEEE - 2019.

4. Kaidar, A.B., Shapkenov, B.K., Kislov, A.P., Zhanat, Zh., Aitzhanov, S.E., Zhakyp, K.B., Fayzulla, D.F., Dzhansarinov, K.E., Ospanova, Zh.M. Zhelenergiyasynn turlendirudin tiimdiligin zhogarylatu. Bulletin of PSU. Energy series. No. 4, 2015. pp. 60-64. ISSN 1811-1858.

5. Shapkenov, B.K., Kaliev, B., Kaidar, A.B. Theory and Practice of Energy Converters. Monograph for students, undergraduates, postgraduates and IT engineers, management and maintenance personnel of power plants / Lambert Academic Publishing, Saarbrücken, Germany, 2014, p. 461.
6. Kaidar, A.B., Shapkenov, B.K., Kislov, A.P., Markovsky, V.P., Zhumadirova, A.K., Shakhman, E.T. Energy-efficient Wind Turbines with Improved Energy Performance. Collection of the International scientific and practical Conference YII Toraigyrov readings. Quality of life in the Pavlodar region. State and prospects, dedicated to the 55th anniversary of S. Toraigyrov Pavlodar State University. - Pavlodar: 2015, vol.5, pp. 293-298. ISBN 978-601-238-552-6.

7. Kislov, A.P., Kaidar, A.B., Markovsky, V.P., Shapkenov, B.K. // The necessity of using accumulators in power supply based on renewable sources / Bulletin of PSU. Energy series. - 2014. No. 2. - pp. 112-117.

8. Kislov, A.P., Kaidar, A.B., Markovsky, V.P., Shapkenov, B.K. // Choosing the topology of an inverter with accumulators / Bulletin of PSU. Energy series. - 2014. - No. 2. - pp. 117-124.

9. Kaidar, A.B., Kopyrin, V.S., Shapkenov, B.K., Markovsky, V.P. // Experimental studies of pulsewidth modulation inverter for power supply systems with renewable energy sources / Bulletin of PSU. Bulletin of PSU. Energy series. - 2014. - No. 3. - pp. 137-143.

10. Kaidar, A.B., Shapkenov, B.K., Markovsky, V.P. / / Evaluation of average and effective values of current, power of static losses at switching stages pulse-width modulation inverter for power supply systems with renewable energy sources / Bulletin of PSU. Energy series. - 2014. - No. 3. - pp. 129-137.

11. Lukutin, B. V.; Sarsikeyev, Y. Zh.; Kaidar, A. B.; Obukhov, S. G.; Kislov, A. P.; Markovsky, V. P.; Shapkenov, B. K.; Akayev, A. M.;Y.Zh. SarsikeyevTurbulentwindcomponent usingKaimal s function, 2014. - № 4. - P . 120-125.

12. Kaidar, A.B. [et al.], Kaidar, A.B., Kislov, A.P., Markovsky, V.P., Shapkenov, B.K., Akaev, A.M. / / Optimization of parameters of power supply systems with the use of system regulation of energy consumption / Bulletin of PSU. Energy series. 2014. - No. 3. - pp. 153-157.

13. Kaidar, A.B., Shapkenov, B.K., Padrul, N.M. // Enhancing the efficiency of wind energy conversion / Bulletin of PSU. Energy series. - 2014. - No. 3. pp. 158-165.

14. Bay, Yu. M.; Rasulov, N. N.; Nosov, A. N.; Kaidar, A. B.; Kislov, A. P.; Markovsky, V. P.; Shapkenov, B. K.;Akayev, A. M.// Cascaded-bridgemultilevel inverterdrives/ Bulletin of PSU. Energy series.2014. - № 4. - P. 27-32.

15. Kaidar, A. B.; Govorun, V. F.; Padrul, N. M.; Volgin, M. E.; Kislov, A. P.; Markovsky, V. P.; Shapkenov, B. K.; Zhumadirova, A. K. // Artificial intelligent applications in condition monitoring and diagnosis of MLIDs / Bulletin of PSU. Energy series. - 2014. - No. 4. - pp. 43-48.

16. Kopyrin, V. S.; Kaidar, A. B.; Ivanova, E. V.; Novozhilov, A. N.; Kislov, A. P.; Markovsky, V. P.;Shapkenov, B. K.; Akayev, A. M. // Diagnostics 
of the fault types and fault locations in a cascaded MLID from its output voltage waveform / Bulletin of PSU. Energy series.- 2014. - No. 4. - pp. 49-58.

17. Lukutin, B.V., Akaev, A. M., Shandarova, E. B., Sarsikeev, E. Zh., Mustafina, R.M., Kislov, A. P., Markovsky, V. P., Shapkenov, B.K. // Stabilization of the output voltage of microhydroelectric power plants through the use of static frequency converters / Bulletin of PSU. Energy series. - 2014. - No. 4. pp. 66-70.

18. Vinogradov, A.V., Vasiliev, A.N. Needs and objectives of implementing distributed energy projects in agricultural holdings, Bulletin of KSPEU, Vol. 11, No. 3 (43) 2019, pp. 13-24.

19. Rasulzoda, Kh.N., Rakhimov, D.B., Safaraliev, M.Kh. Influence of short-circuit current in power lines on the value of current in the field windings of a hydrogenerator, Bulletin of KSPEU, Vol. 11, No. 3 (43) 2019, pp. 99-108. 